elaboration of detail. We could have wished, indeed, that details had been inserted somewhat less profusely. It can nevcr be possible in maps of the scale of this one (about one-quarter of an inch to a mile) to render, with a sufficient degree of clearness, all the minutia which are inserted in the great Government Surveys of civilised countries; nor can it ever have been supposed that this map would do away with the necessity of smaller maps of separate districts on a larger scale. Yet we find, in the map under review, in innumerable places, a mass of details which would have been amply sufficient had it been four times its dimensions, and a consequent want of clearness which is not a little perplexing. In some places, even the fantastic passes made in late years by the followers of the high art of mountaineering hate been inserted, whilist in others (in the chain of Mont Blanc, for example) they have been almost entirely omitted, simply from want of space. Thus it appears, to those who are not informed, that in some places there are a great number of such passes, and in others scarcely any, when the reverse is perhaps the case. We should have advocated, both for the sake of consistency and of clearness, the omission of all passes except those of distinct utility.

In point of cleamess it must be admitted that the English Alpine Club Map is scarcely equal to the reduction of the Carte Dufour which was published last year in Switzerland, * and this is not surprising. The authorities at Bern had to produce a simple reduction of the twenty-five sheet map of Switzerland, which was intended to be useful for general purposes, and to be issued at a low price so that it might be within the reach of everyone, and in this they have succeeded admirably. They had at their command most of the members of the staff who had becn employed upon the survey, and thus had little or no difficulty in determining what to omit. This was a great advantage; for it must bc obvious to all that, in reducing a map to a much smaller scale, it is more easy to determine what should be inserted than it is to know what should be left out. This simple fact, no doubt, accounts to some extent for the over-elaboration of the Alpine Club Map to which we just now referred. Its projectors also adopted the Carte Dufour as the basis of their map so far as Switzerland was concerned, but they had not the command of the very exact and minute topographical information which was possessed at Bern.

The reduced Swiss map, like the Carte Dufour, is a map of Switzerland, and for the most part stops abruptly at the frontier. The English map, however, is a map of Switzerland with parts of the neighbowno conntrits. I exiends everywhere sixteen miles more to the south than the most southern point of the Swiss boundarics, and in some places the country which it embraces (which is not included in the Swiss map) is as much as sixty-five to seventy miles from north to south. In the north and in the west the limits of the two maps are nearly the same, but in the east the English one includes the Orteler and scveral other important greups of mountains, which are not given in the Swiss one. The superficial area of the Alpine portion of the English map is altogether about one-half greater than that of the other, and the chief value of the map will be found to be in the part of it that represents this land beyond, but bordering the Swiss fronticrs.

It was a comparatively easy task, notwithstanding the complicated and exceedingly elaborate nature of the engraving, to render Switzerland after the Carte Dufour. The chief difficulty in the production of the map has lain in obtaining the material necessary for its completion towards the south. When it was commenced-now nearly ten years ago-there was no map, even respectably accurate, of the chain of Mont Blanc in existence ; and thence, right away to the furthest land in the east which is

* Karte der Schweir, in 4 bhittern, rednciert unter der Direction des Herm General G. H. Dufout. Maassab, 2 thot $^{2}$ (Dern, i $S_{73}$ ) included, scarcely a square league could be adopted with confidence from any published survey. Hence it was necessary not only to cxamine every individual mountain and valley, but absolutely to re-survey several large districts. The chain of Mont Blanc, as it appears in the Alpine Club Map, is mainly taken from the special survey of Mr. Adams Reilly; * and so, too, is the whole of the southern side of Monte Rosa, as well as the large district bounded on the east by the Val d'Ayas, on the south by the valley of Aosta, and on the west by the valley of Valpelline.t This Iast-named district alone includes more than 150 square miles. The Graian Alps were in a state of hopeless confusion when Mr. R. C. Nichols took them in hand, and anyone who compares the map moler notice with the best which were published previously will see what radical changes and corrections have been effected. Altogcther, there is in the Alpine Club Map not less than a thousand square miles which have been entirely remodelled, and, for the most part, re-surveyed : this, moreover, being some of the most rugged and dificult country in Europe, containimes numerous peals from $12,000 \mathrm{ft}$. to $13,000 \mathrm{ft}$. elevation.

Those who have been concerned in the production of the Alpine Club Map of Sivitzerland have a right to be proud of their work. We have tested it in the Alps, and it has stood the scrutiny extremely well. We cordially hope, though scarcely expect, that it will prove remunerative to its publisher, and that he will be induced to complete it by adding sheets to the east and to the west, so that at length there may be at least on map of the grandest and most picturesque chain of mountains in the world. In conclusion, a word is due to the engravers. The work was commenced by the late Dr. Keith Johnston, but the greater and the most difficult portions have been executed by Mr. John Addison. We have rarely seen better hill-engtaving ; and the wonder is, not that the appearance of the map has been delayed so long, but that a work of such maguitude and extraordinary minuteness should have been completed so soon.

E. WV

\section{REPORT OF PROF. PARKER'S HUNTERIAN LECTURES "ON THE STRUCTURE AND DEVELOPMENT OF THE VERTEBRATE} SKULL" "

VIII.--Shuli of the Common Fowl (Gallus domesticus).

$T$ HF skull of birds is romarkabic for the great amount of anchylosis which takes place between its various constituents long before the period of adult life. So complete is this union, that the determination of the separate bones in a full-grown bird is a perfectly hopeless task, without first studying their relation at a period when they retain their criginal distinctness. It will therefore be convenient to describe the fowl's skull, in the first instance, at the pcriod of hatching, when the chicf ossific centres are still separate, although most of the distinctive characters of the adult are already assumed.

In this stage the foramen magnum is surrounded by the four perfectly distinct elements of the occipital segment, between which extensive tracts of cartilage still exist. The basi-occipital is comparatively small, and forms almost exclusively the rounded condyle (Fig. 27 $0 . \mathrm{C})$; the cx-occipital and supra-occipital are large and expanded, and into the latter extends the anterior semicircular canal (Fig. 26, a.s.c.), so largely developed in birds. The prootic (Fig. 26, Pr.O) is well seen on the inner sicle of the cranial cavity, but outside is completely hidden by the great development of the squamosal, which takes a very considerable share in the formation of the side wall of the skull. Two other auditory bones have 
appeared-the opisthotic (Op.O) and the minute epiotic Ep.O); the latter attains a much greater size before it fuses, in adult life, with the supra-occipital. The main part of the skull floor is formed by the large, laterally expanded basi-sphenoid, which above is excavated into a deep sella turcica for the pituitary body, and in front passes into the interorbital septum and the bony rostrum

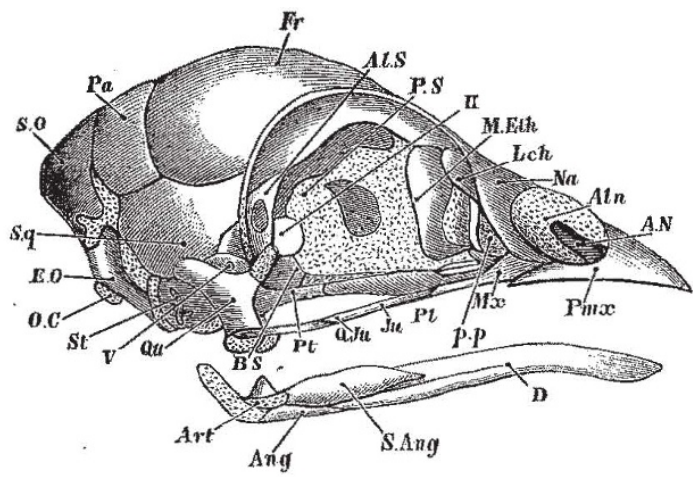

Fig. 25-Skull of Fowl at the period of hatching (side view). p.p, pars plana

supporting it, being, in fact, firmly anchylosed with the latter. A careful study of the earlier stages of development shows that only the upper part of this bone is really homologous with the basi-sphenoid, the lower part being the representative of the hinder part of the parasphenoid. The basi-temporal (Figs. 26 and $27, \mathrm{~B} . \mathrm{T}$ ), as this large membrane bone is called, is firmly anchylosed with the basi-sphenoid, the greater part of the inferior surface of which it completely covers, but is at this period still partially distinct from the representative of the anterior part of the parasphenoid (Figs. 26 and 27, Pa.S), the "basi-sphenoidal rostrum" so characteristic of birds, which is, however, united with the basi-sphenoid.

In front of the depressed basi-sphenoidal region the basis cranii becomes much compressed from side to side, forming a large cartilaginous interorbital septum, the representative of the prepituitary part of the basi-sphenoid and the presphenoid behind, and of the mesethmoid in front. The walls and roof of the brain-case are completed by the squamosals, alisphenoids, parietals, and frontals; the latier also affording support to the fore part of the base of the brain by means of their extensive in-turned orbital processes. The orbito-sphenoids are altogether absent at

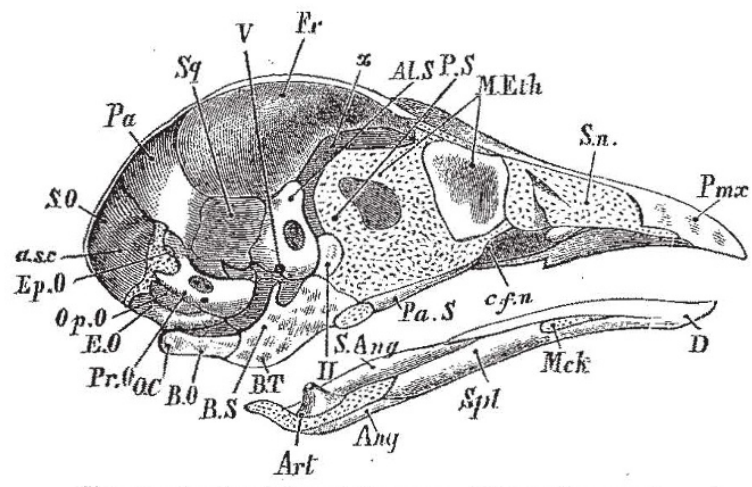

FIG. 26.-Sectional view of the same. B.T, basi-temporal.

this stage, but at a later period are represented by two pairs of insignificant ossifications above the posterosuperior edge of the presphenoid in the membranous space marked $x$ in Fig. 26.

A. considerable portion of the anterior or ethmoidal part of the interorbital septum is already ossified, forming the lamina perpendicularis, or mesethmoid (M. Eth).
In front of this the cartilage is continued almost to the end of the beak as the septum nasi (Fig 26, s.n), or wall between the nasal sacs, the upper margin of which is produced outward into a wing-like expansion, the alinasal cartilage (Fig. 25, Aln) pierced by the external opening of the nostrils (A.N). A further continuation of the same median cartilages is seen in the slender pre-nasal or basitrabecular (Fig. 27, B. Tr).

Within the nasal cavity are three pairs of cartilaginous folds, the alinasal turbinals represented by valvular processes of the ala nasi. in some mammals, and the upper and lower turbinals, homologues of the structures bearing the same name in the higher class. The sole representative of the middle turbinal is the flat hinder wall of the ethmoid looking into the orbit, and known as the pars plana (Fig. 25 , p. p).

There is one more point of importance to be noted with regard to the interorbital septum, namely, the craniofacial notch (Fig. 26, c.f.n), a natural separation between the epi- and cerato-trabecular elements, and of great functional importance in the bird, where the beak is moveable upon a sort of ' hinge formed by the premaxillæ just above this point.

The membrane bones of the face are yet to be considered. The premaxillæ are large bones partly fused

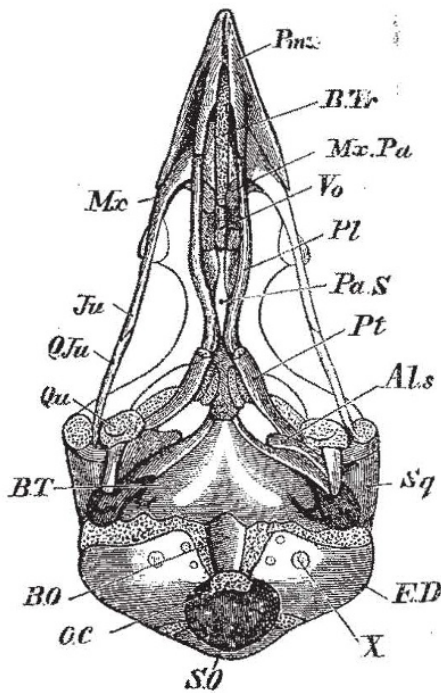

Fig. 27.-The same from beneath. $\mathrm{Mx}$. $\mathrm{Pa}$, maxillo-palatine process.

together in the third line, and provided with well-developed nasal, palatine, and maxillary processes. . On either side of the former of these backward projections are situated the nasals, processes from which come downwards and forwards to bound the alinasal cartilage posteriorly. The lacrymal is a largeish bone lying in the upper part of the front wall of the orbit, articulating with the nasal, and directed outwards and backwards.

The bones of the upper jaw, or palato-maxillary apparatus, consist of two sub-parallel series, each of which articulates in front with the premaxilla, and behind with the quadrate; in the outer series are contained the maxilla, jugal, and quadrato-jugal, in the inner the palatine and pterygoid. All the bones in the former category are extremely slender-almost filiform, in fact ; the palatines and pterygoids, on the contrary, attain a high degree of development, but neither they nor the maxilla develop palatine plates, the only rudiment of those structures being in the maxillo-palatine processes ( $\mathrm{Mx} . \mathrm{Pa})$, flat plates of bone proceeding inwards from the maxillæ beneath the palatines to meet the small, single vomer. The palate of the fowl is thus formed on the simplest schizognathous type. 
The quadrate is a stout bone, having three well-defined processes, one forming the articular surface for the mandible; a second, answering to the otic process of the primitive suspensorium, articulates with the squamosal; and the third, or orbital process, projecting forwards and upwards, is the pedicle or true apex of the mandibular arch. The otic process, besides articulating with the squamosal, bears a small facet for the prootic; this, in many birds, is developed into a distinct secondary head.

Immediately behind the quadrate is seen the large tympanic cavity; this is banded above by the supra-occipital and squamoid, below by the basi-temporal, behind by the ex-occipital, and in front by the basi-sphenoid; it sends into the latter a diverticulum, the anterior tympanic recess, and a second or posterior recess into the supraoccipital, through the diplöe of which it is continuous, as in the crocodile, with the tympanum of the opposite side. The fowl resembles the ostrich, and differs from most other birds in being wholly devoid of a tympanic bone.

The lower jaw consists of the same elements as already described in the snake, except that the coronary is absent in the fowl, though present in most birds; in this stage the five bones (articular, angular, supra-angular, dentary, and splenial) are perfectly distinct, and Meckel's cartilage yet remains of considerable size.

The upper part of the hyoid arch is separated, as in the snake and frog, to form with the stapes a columella auris. From the oval, irregular, plug-like stapes proceeds a slender rod of bone terminated by a triradiate cartilage, of which the slender antero-inferior bar is the infrastapedial, the broad somewhat expanded central segment the extra-stapedial, and the postero-superior bar the supra-stapedial. The latter is connected by an oblique bar with the extra-stapedial. The stylo-hyal is represented by the free end of the infra-stapedial.

The tongue-bone consists of a body made up of glossohyal (formed by the union of the lesser cornua), basi-hyal, and basi-branchial (uro-hyal) arranged in a linear series; and of two pairs of cornua, the anterior or cerato-hyals, very small, and forming more lateral projections to the body, and the posterior or epi- and cerato-branchials (thyro-hyals), long and elastic, and embracing the occipital.

The development of the fowl's skull has been worked out as far back as the fourth day; but even at that early period, when chondrification is only just beginning to set in, it is impossible to demonstrate with certainty the distinctness of many regions which are perfectly separate at corresponding stages in the lower types. At the period mentioned, the indifferent tissue of which the trabeculae are formed is perfectly continuous with that of the investing mass, and this again with that of the auditory capsules. When, however, the process of conversion into cartilage is complete, the apices of the trabecula become perfectly distinct from the investing mass, and form a pair of backward-turned horns (often called the lingita sphenoidales) on either side of the pituitary space. The ear capsules, on the contrary, remain as undistinguishable from the para-chordal region after chondrification as before, and only acquire distinctness by ossification. This rapid process of fusion which takes place equally between the masses of indifferent tissue constituting the primordial skull, in the subsequently formed tracts of cartilage, and in the various ossifications of a still later period, renders the study of the bird's skull one of the most difficult problems of craniology.

The manner in which the hyoid arch is developed has been worked out more exactly in the house-martin than in the chick, in which, however, the process is essentially similar. At a very early period the upper end of the arch grafts itself on to the auditory capsule, and at the same time becomes split up into three portions. The proximal of these constitutes the columella, a plug of the auditory capsule being before long cut out around its attached end to form the stapes. The middle is the stylo-hyal; it is at first connected to the columella by a tract of tissue, but afterwards fuses with the infra-stapedial element of the latter. The distal portion never becomes chondrified in its upper portion, resembling in this respect the corresponding structure in man (the stylo-hyoid ligament), but below forms the lesser cornu of the hyoid bone, or cerato-hyal.

The mode of formation of the complex basi-sphenoidal region is, perhaps, the most important point which yet remains for consideration. No endogenous ossification takes place in the cartilage of this part of the basis cranii, but a pair of symmetrical ossific centres make their appearance in the thick web of perichondrium which underlies it, a third (median) centre appearing at the same time in front of the other two in the fibrous tissue below the ethmoidal cartilage. These ossifications together represent the dagger-shaped paraspherioid of the frog; the anterior is commonly known as the basisphenoidal rostrum; the posterior pair, coalescing, form the basi-temporal. Before they unite, however, ossification extends from them into the overlying cartilage, and thus the true basi-sphenoid is formed in a manner perfectly unique among vertebrata.

\section{THE NEW VINE-DISEASE IN THE SOUTH. EAST OF FRANCE *}

II.

HAVING thus far studied the spread of the new vinedisease and the extent of the ravages committed by the Phylloxera, it is time to turn our attention to the insect itself, and to state the results of scientific observation of the manner in which it attacks the vine rootlets, and the various circumstances and conditions which either favour or retard the development of the disease.

The Phylloxera is a very minute insect, measuring, when fully grown, not more than $\mathrm{x}-33 \mathrm{rd}$ of an inch in length. Its most striking feature is its proboscis, which lies in a sort of groove on the under-side of the insect, and with which it pierces the roots on which it feeds. This proboscis is very slender, and appears to be formed of three tongues, a greater one in the middle, and two more slender and shorter, on the two sides of it; it resembles a brown thread bending round and inserting itself in the tissue. The base of the proboscis is a sort of

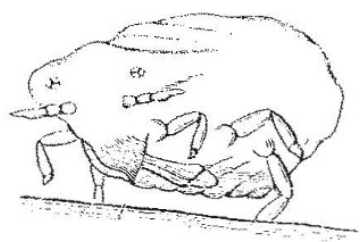

The Phylloxera.

flat and sharp-pointed blade, composed of brown parts which prolong themselves into the tongues. The animal raises this blade a little in applying its proboscis to its food. The length of the sucker is equal to about half that of the body of the Phylloxera, which does not bury more than half of it in the bark of the roots. By this sucker the insect fixes itself to the spot which it has chosen, so that it can be made to turn upon it as on a pivot. In colour the Phylloxera, during the summer at least, is yellow, but in the late autumn it turns to a copper-brown tint, which lasts through the winter. The active life of the Phylloxera lasts from the beginning of April till the latter half of October. The insect hibernates through the other months, though previous to the commencement of hibernation the females who have laid eggs during the

$$
\text { * Continued from vol, x. p. } 306
$$

